\title{
Critical Discourse Analysis of News Discourse
}

\author{
Qin Xie \\ Shanxi Normal University, China
}

\begin{abstract}
News discourse is one of main analysis subjects of critical discourse analysis. People can know the opinions implied by the author and grasp the real situation of the events described in the discourse by critical discourse analysis. Furthermore, it is beneficial for the audience to establish the critical awareness of News discourse and enhance the ability to critically analyze news discourse. Based on the discussion of the concept of news discourse and critical discourse analysis, the theoretical foundations and steps of critical discourse analysis, the paper illustrates the method of the critical analysis of news discourse. The author also puts forward issues that needed to pay attention to in order to improve the ability of news discourse analysis.
\end{abstract}

Index Terms - news discourse, critical discourse analysis, method, emphases

Critical discourse analysis can provide some guidance for the analysis of news discourse. Knowing the theoretical basis and analytical method of critical discourse analysis is beneficial to understand the actual situation of the events described in the news discourse and the implicit ideological content in news discourse. The paper explores the elements and the steps of the critical discourse analysis of news discourse.

\section{The ConcePt of News Discourse ANd Critical Discourse ANalysis}

\section{A. The Concept of News Discourse}

News discourse, a vital field of linguistic research, is always seen as an objective and formal linguistic form of discourse. However, the definition of news is rather elusive. Linguistic scholars and journalists have given different versions to define it, but no one has been generally accepted in the world up to now.

News must be something extraordinary and particular enough to attract the public's attention, just as the classic comment, "When a dog bites a man, which is not news, because it happens so often. But if a man bites a dog, it's news." (Rule and Anderson, 2003)

According to Ekstrom (2002), news is "reliable, neutral and current factual information that is important and valuable for citizens in democracy" (p.259). Fowler (1991) holds that "News is not a natural phenomenon emerging straight from 'reality', but a product. It is produced by an industry, shaped by the relations between the media and other industries, by the bureaucratic and economic structure of that industry, and most importantly by relations with government and with other political organizations." (p.223)

Even if there is no a common accepted definition of news, all the above-mentioned versions are mutually complementary. In order to facilitate the study of the paper, the author borrows from various versions of news. News is the information that is published in newspaper, broadcasted on radio, played on television, and reported on the Internet about the current events taking place in a particular area or in the country or in the world. It plays an important role in modern society and becomes a window that people acquire knowledge about the world by virtue of its advantages such as timeliness and objectivity, etc. Information provided by the news reports has the function of leading the public. In the official news reports, due to the influence of factors such as value orientation, there is the ideological content hidden in discourse, which usually tends to be misunderstood by the audience.

\section{B. The Concept of Critical Discourse Analysis}

Critical discourse analysis is a field that is concerned with studying and analyzing written and spoken texts to reveal the discursive sources of power, dominance, inequality and bias. It examines how theses discursive sources are maintained and reproduced within specific social, political and historical contexts (Van Dijk, 1998). In a similar vein, Fairclough (1995) defines critical discourse analysis as:

Discourse analysis which aims to systematically explore often opaque relationships of causality and determination between (a) discursive practices, events and texts, and (b) wider social and cultural structures, relations and processes; to investigate how such practices, events and texts arise out of and are ideologically shaped by relations of power and struggles over power; and to explore how the opacity of these relationships between discourse and society is itself a factor securing power and hegemony (p.135).

Ruth Wodak (2000) defines it as "an interdisciplinary approach to language study with a critical point of view" for the purpose of studying "language behavior in natural speech situations of social relevance." (p.264)

In short, critical discourse analysis aims at making transparent the connections between discourse practices, social practices, and social structures, connections that might be opaque to the layperson. Linguists advocate that the use of stylistic analysis techniques traditionally employed in the literary discourse for the analysis of the non-literary discourse. Therefore, critical linguistics put their stress on the interactions that exist in the discourse and the social structure. Wu 
Hongyan (2008) said: "The abilities to appreciate and criticize the language use can be improved by means of the critical analysis of the public discourse. So that they can better deal with the increasing involvement of language in social life nowadays." said Wu Hongyan. ( p.332)

\section{The ThEORETICAl Foundations of CRITICAL DisCOURSE ANALYSIS}

\section{A. The Linguistic Foundations of Critical Discourse Analysis}

The linguistic bases of critical discourse analysis include the discourse analysis theory of the Foucault School and British-American School. Critical discourse analysis firstly obtains relevant theoretical basis from Critical Linguistics. Besides, it draws on Halliday's analytic method, which includes systemic-functional linguistics and the content of regarding language regarded as social semiotics.

With the development of critical linguistics, critical discourse analysis gains new understanding from the post-structuralism linguistics, that is, language and discourse are not neutral or overt means. Both of them are not only closed related to knowledge and the social relationships, but also play important roles in constructing and embodying human beings' social behaviors and identities. Post-structuralism linguists claim that knowledge people all have is from the discourse. In other words, history and culture often is the collection of the discourse. Meanwhile, it studies the dialectical relationships between discourse and power, that is, the discourse can embody power. Conversely, power is realized by the discourse, and it controls and influences the discourse. Therefore, the discourse or the text is closely related to power. Post-structuralist discourse theory has important implication for critical discourse analysis, that is, discourse is historical and specific, and its underlying meaning changes with conditions such as time, circumstance, etc. Critical discourse analysis refers to Foucault's social opinions about the discourse, and develops the viewpoints on one-way construction, including the discourse not only can reflect the social reality, but also influence the construction of the reality. So it is believed that discourse analysis not only can reveal the social reality accurately, but also is helpful to construct the social reality.

In addition, systemic-functional grammar has an impact on critical discourse analysis. Halliday (2001) suggests that social culture's aspects constitute the building of the social realistic meaning from the perspectives of sociology and anthropology. Moreover, he (1994) believes that language has three functions, including the ideational function, the textual function and the interpersonal function. Besides, both of the discourse genre and the language choice are closely related to the register of language use, and the structure, field, tenor, and mode of the discourse subscribe to its social purposes. (Halliday, 2001) In the framework of the systemic-functional grammar, language is closely related to the social structure and the social cultural background, etc. The reason why Language form is mainly determined by its social functions should be revealed from the perspective of the discourse's social communicative function. Remarkably, Post-critical discourse analysis theory suggests that language is a kind of the social practice to some extent, and the discourse is not only regarded as the form of language, but also crystallized as the social practice. In essence, critical discourse analysis studies the society from the linguistic level, and it connects the language analysis with the society analysis.

Obviously, the language views of critical discourse analysis do not conflict with the language view of systemic-functional linguistics in the matter of language having the social functions. There are two keys to both of them. Firstly, the functional linguists affirm that language has the social functions. Moreover, the language analysis not only can reveal accurately what the features of language are, but also uncover the process of people choose language according to their needs. In conclusion, Critical discourse analysis majorly emphasizes the discourse's social functions aspect. "Because the discourse and the society are interstructive, the aims of the language analysis are to reveal the interstructive relationships, the underlying power relationships and unequal relationships in the discourse." (Wei Xinxin, 2010, p.164)

\section{B. The Literary Criticism Foundations of Critical Discourse Analysis}

Critical linguists draw on the method of regarding literary discourse as the research subject. In the filed of western stylistic research, stylists pay attention to study the specific process of the discourse generation and the relationship between the discourse and the social and historical context of the discourse. Therefore, the basic task of literary criticism is to exam the operation process of language in the social and historical context.

Critical discourse analysis borrows from M·Bakhtin's (1963) research method that he puts his stress on analyzing the dialogicality of the dis course. In other words, he emphasizes the intertextuality analysis. It refers to the different relationships such as synergies and constraints generated from different discourse in the process of the small discourse forming the large discourse. These relationships have various effects on other discourse. Naturally, discourse is influenced by a variety of genre that already existed. The author of the discourse usually creates new idea by reconstructing the different form of genre, which affects the social and cultural structures and promote the change of society effectively. Critical discourse analysis borrows from the above concept, and further puts forward the important forms of the discourse power struggle: intertextuality and dialogicality. Different texts are interwoven into the text through discourse, the meaning of the text is completed by the negotiation of the multiple coexistence discourse in the text. Therefore, the aims of uncovering the implicit power relationships and unequal relationships in the discourse can be achieved by analyzing the dialogicality and intertextuality of the discourse. 


\section{The Steps of Critical Discourse Analysis of News Discourse}

It is believed that we should pay attention to the practicality when we analyze the news discourse by critical discourse analysis. Because critical discourse analysis is limited by the world views and thoughts and feelings, etc. So it is difficult to analyze the specific discourse. Meanwhile, critical discourse analysis usually causes different levels of ideology analysis when we analyze the news discourse by it. In the framework of critical discourse analysis, it highlights its practicality when we analyze the news discourse. So we should do several things to help the audience to analyze the news discourse. For example, we need to seek or design some objective and practical analysis methods. Besides, we should list some relevant structures and combinations that may contain or be used to express meanings. Meanwhile, critical discourse analysis of news discourse is supported by the critical linguistics, including systemic-functional linguistics and transformation-generative grammar, etc. From the above, we suggest that we should start the critical discourse analysis of news discourse by means of the following steps.

Firstly, we should analyze structure features of the news discourse. Meanwhile, we need pay attention to connect the techniques or processes that occur in the discourse generation. For example, we analyze the news discourse that employs lots of passive structures and gerunds. It is reasonable for us to regard them as passivization or nominalization, because the generative process of the two kinds of discourse is fully reflected in the news discourse. Secondly, we need to demonstrate these basic techniques or processes are relevant to the meaning of ideology in the process of generation or understanding of the news discourse that we analyze. For example, the specific process has the functions of the social and the historical phenomenon in the news context. Lastly, we should pay attention to demonstrate the social functions of ideology hidden behind the language structure and processes, which can intervene in a social process such as maintaining a kind of power relationship, etc.

\section{The Example of Critical Discourse Analysis of News Discourse}

With the development of the study of the critical discourse analysis, the news discourse has received more and more attentions as an important area of critical discourse analysis. Nowadays, the English news discourse influences the public opinion in the world every day, because the English mass media is increasingly penetrating into all aspects of the international community. News is not absolutely objective and fair, a lot of news discourse appears to be objective and fair, but they contain ideological content, which have a subtle effect on the audience.

After the bullet train crash occurred on July 23, 2011 in Wenzhou, there were various reports on the railway traffic accident both at home and abroad. The American mainstream media always claims that its news is objective and fair, but that is not the case. The paper takes a report on the railway traffic accident of the New York Times as an example to conduct the critical discourse analysis of news discourse.

\section{A. The Lexical Choice of News Discourse}

The reporter establishes the social relationships between people in news discourse by lexical choice. That is, lexical choice is significant for news discourse analysis. For example, Nominalization refers to the addresser expresses his or her meaning by employing the noun or noun phrase instead of the verb structure or sentences. It can create a impersonal effect by deleting the modal part, blurring the concept of time, and dissimulating the participants of the process or the causality, etc. Besides, passivization has functions of covering cause-effect relation and providing the convenience to the actor. In the following, we will study the lexical choice by analyzing the nominalization and passivization of news discourse in the following.

(1) The government's only explanation for Saturday's accident has been that a lightening strike disabled equipment.

(2) Immediately after the accident the government dismissed three more railway officials without explanation, and announced a thorough investigation into its cause.

In example (1) and (2), we can see that "explanation" is the noun form of "explain", the reporter blurs the subject, time and degree of "explain" by employing "explanation". The information conveyed for the audience is not comprehensive. Therefore, It is likely that they understand China government's explanation for the accident unilaterally.

(3) A railway communications officer, identified only as Mr. Liu, told the BeiJing Times that after the accident, he was sent to check the communications system of the first train.

(4) In China, a torrent of public criticism continued Tuesday, with bloggers and citizens asking why the government was not more forth coming about the cause of the crash, why parts of the wreckage were buried at the site and why a toddler was found alive in the wreck even after railway authorities had sad there were no further signs of life.

In example (3), action of "send" originally can be expressed in the active form. However, the reporter uses the passive form, which conceals the action and the executor of "send". So the reporter omits the main information to convey the message that there was someone to investigate the accident, which affects the objectivity of the fact. Therefore, we can see that the western media influences the public in a subtle way. From example (4), the use of the passive voice "buried" obscures the time and the indicator of the action, which leads to the audiences to assume that the burial was directed by the Chinese government. Besides, the subject of the passive voice "was found" is "toddler" that is highlighted as the subject, which expresses the cruelty of the accident indirectly. Meanwhile, it also implies the wrong information that the Chinese government does not value human rights. This also is the distortion of the image of China. 


\section{B. The Practice Level of News Discourse}

News discourse can fully reflect reality and its objectivity by employing the reported speech. It includes direct speech and indirect speech. Direct speech refers to the information that derives from the party, the insider and the authority. It has the function of enhancing the authority of news discourse. However, indirect speech is paraphrased by the quoter. Due to the reporters' different attitudes and understanding of the original work, they express their different positions and views in the process of paraphrase. We analyze the news discourse by studying its reported speech in the following.

(5) "There appear to have been some irregularities in the high-speed rail program," said Richard DiaBona, a transportation specialist at LLA Consultancy in Hongkong. "Maybe this was corruption or substandard work, or perhaps things were put into place too fast"

(6) "This is extremely rare," said Vukan R. Vuchic, a rail expert at the University of Pennsylvania. "I have never heard of lightning doing that, but if it did, everything else would stop too. And the signal system should keep trains at a safe distance.

In example (5), we can know that the reporter wants to indicate his attitude toward the accident indirectly by quoting an authoritative expert's utterance directly. Naturally, he is able to achieve his aim of controlling reader's mind. Meanwhile, in example (6), the reporter quotes the discourse of a railway expert at Pennsylvania University, which reveals contempt for China. The reported speech has a preconceived effect on the audience. This is the manifestation of the western mainstream media's ideological pervasion of the public.

(7) Six minutes after her train left the station, she said, it slowly came to a stop on the tracts and paused five or six minutes. It had just started moving again when the other train plowed into it.

(8) A railway communications officer, identified only as Mr Liu, told the Beijing Times that after the accident, he was sent to check the communications system of the first train, which was working, he said, raising the question of where the communication breakdown occurred.

From example (7), we can see that it is an indirect speech. The reporter paraphrases a passenger's description about the accident. Using indirect speech not only can enhance the persuasiveness of the news discourse, but also leave room for imagination. Meanwhile, in example (8), the reporter expresses his doubt about the location of the communication system breakdown by quoting the discourse of a railway official who is not willing to reveal his name indirectly.

\section{The Social Functions of News Discourse}

There is the dialectical relationship between news discourse and the social structure. Discourse is composed of the social structure and subject to the social class and the social structure. Meanwhile, it has corresponding social functions, because discourse has an effect on the social structure. Therefore, the critical linguists suggest that language use is an important form of the social practice. What they advocate is to connect the social analysis with the linguistic analysis.

From the above-mentioned analysis of the American media about the rear-end collision in Wen Zhou. We can know that the American media emphasizes the negative images of China. Essentially, the phenomenon is caused by the conflicts between China and the United States for a long time. Yuan Jiuxia (2009) said: "The American media has always wanted to derogate the image of China. Therefore, its media is bound to do everything possible to create China's negative images". (p.124)

\section{The Important Parts of News Discourse Analysis}

We should pay attention to the following aspects when analyzing news discourse by critical discourse analysis.

\section{A. The Issue of Exploring "Why” in Language Expression}

There is the positivist tendency in the former English linguistics, which focuses on the true and objective language description, values the content of language ("what"), and neglects the reasons of using language ("why"). The critical analysis of English news discourse happens to solve the important question of "why" of language expression. At present, the dominant view of critical linguistics is that the differences in the structures of language forms are determined by its basic functions, which not only can reflect the ideology accurately, but also reinforce the differences. However, all of these can be explained from the perspectives of the social structures and power relationships.

\section{B. The Accuracy of News Discourse}

The western government and media always preach to the world their peculiar idea that people can enjoy the so-called freedom of speech and press fully in western society, and their news reports are objective and fair. After analyzing the news reports carefully, we can find that the western media do not report objectively, but choose the subject and content according to its needs. It is necessary to talk about the greatest power of media is that it can express the voice of the specific group by employing the responding events at the appropriate time. The content involved in the news discourse seems to reflect people's thoughts and feelings and ideology. Therefore, critical discourse analysis puts its emphasis on analyzing the ideology tendency of new discourse, and studying the relationship between the source of news discourse and the reporter's position as well as viewpoints.

\section{The Emphases of News Discourse}


We should keep our eyes on two things when analyzing the important parts of news discourse by critical discourse analysis. Firstly, we need to analyze its semantic category and rhetoric devices. Secondly, we also need to study the interest of the social class that presented by the discourse and the implicit ideology of the group and institution in the news discourse. The ideology is not totally expressed by the reporter, but reflected through his or her cultural background, educational status and occupation, etc. Fan Lidong (2009) said: "Knowing this, we can see how state power and media rights influence the ordinary audience through the news discourse" (p.10)

\section{The Intertextuality of News Discourse}

Intertextuality is a prominent feature of news discourse. Almost all the news discourse contains reported speech. There are a variety of forms of direct and indirect speech as well as other persons' discourse without explanations. Generally, they have different themes or stylistic features, which represent the interests and ideology of the rightsholders. We can find the implicit ideology and power relationships in news discourse if analyzing its intertextuality deeply. However, the boundaries of intertextuality are not very clear. It is difficult to make clear analysis of the discourse. Therefore, we should lay stress on studying the pragmatic functions of intertextuality in the new discourse. Generally speaking, the reporter reconstructs intertextuality material according to logical relationships and semantic structure inside the news discourse. Xin Bin suggests (2000) that the key of analyzing intertextuality is to exam its semantic and pragmatic functions by studying the harmonious degree and concrete way of combining of the intertextuality material in News discourse.

\section{CONCLUSIONS}

From the above-mentioned, we should pay attention to the basic knowledge of the discourse analysis. It is necessary to master the basic theory of critical discourse analysis such as systemic-functional grammar. Besides, we need to know the steps of critical discourse analysis of news discourse. Lastly, it is important to lay stress on other aspects such as the accuracy, emphases and intertextuality of news discourse. Only in this way can we further improve the ability of news discourse analysis and understand its deep meaning as accurately as possible.

\section{REFERENCES}

[1] Bakhtin, M.M. (1963). Problems of Dostoevsky's Poetics, (Russian) Moscow: Khudozhestvennaja literature.

[2] Dan Shengjiang. (2011). Critical Discourse Analysis of News Discourse. Foreign Language Education, 6, 78-81.

[3] Du Ting. (2011). Discourse Analysis of American News Discourse. Youth Journalist, 10, 34-35.

[4] Ekstrom. (2002). M. Epistemologies of TV Journalism: A theoretical Framework. Journalism 3, 3, $259-282$.

[5] Fairclough, Norman. (1995). Critical Discourse Analysis: The Critical Study of Language. London: Longman.

[6] Fan Lidong. (2005). Critical Discourse Analysis of Two Current News Reports. Journal of NanTong Vocational \& Technical Shipping College, 4, 7-10.

[7] Fowler, R. (1991). Language in the News: Discourse and Ideology in the Press. London/New York: Routledge.

[8] Halliday, M. A. K. (1994). An introduction to Functional Grammar. London: Edward Amold.

[9] Halliday, M. A. K. (2001). Language as Social Semiotic: The Social Interpretation of Language and Meaning. London: Edward Amold.

[10] Itule, D. B. \& Anderson, D. A. (2003). New Writing and Reporting for Today's Media. (6 ${ }^{\text {thed}}$ ). Beijing: China Renmin University Press.

[11] Van Dijk, T.A. (1985). Handbook of Discourse Analysis. London: Academic press.

[12] Wei Xinxin. (2010). Theoretical Basis and Analysis Method of Critical Discourse Analysis. Southeast Academic Research, 1, 162-168.

[13] Wodak, R. (2009). The Discourse-historical Approach. In Ruth Wodak \& Michael Meyer (Eds.), Methods of Critical Discourse Analysis (2 nd edn). London: Sage, 263-265.

[14] Wu Hongyan \& Xu Yan. (2008). News Discourse and Critical Discourse Analysis. Anhui Literature, 7, 332-333.

[15] Xin Bin. (2000). Critical Linguistics and Critical Analysis of English News Discourse. Foreign Language Education, 21, 44-47.

[16] Yuan Jiuxia. (2009). A Critical Discourse Analysis of News Discourse: A Case Study of Snow Storm Reports in Early 2008. Journal of HuNan First Normal College, 9, 123-124.

Qin Xie was born in Lin Fen, China in 1992. Now, she is a linguistic postgraduate, studying at Shanxi Normal University. She has been a teacher at a junior high school in 2015. Her research interests include critical discourse analysis and second language acquisition. 